\title{
MUSEOLOGIA SOCIAL E SOCIOLOGIA DAS AUSÊNCIAS NO CONTEXTO DA AMAZÔNIA BRASILEIRA: UMA APROXIMAÇÃO TEÓRICA.
}

Marcelle Pereira $^{1}$

\section{Resumo}

Este artigo tem como objetivo estabelecer uma aproximação teórica entre a Museologia Social e os pressupostos da Sociologia das Ausências, a partir de uma análise preliminar dos conceitos de monocultura e ecologia veiculados pelo sociólogo português Boaventura de Souza Santos. As monoculturas são responsáveis pela proliferação das invisibilidades sociais e, a partir delas, as ecologias surgem como alternativas que possibilitam a visibilidade das práticas sociais silenciadas e, por conseguinte, em processo de esquecimento. A museologia social, por sua vez, tem se dedicado em transformar processos sociais marginalizados em narrativas e iniciativas museais que possibilitam a reflexão e a participação cidadã a partir de uma perspectiva que compreende o museu como espaço que pode atuar na desconstrução das formas sociais de produção de não existência. Assim, a museologia social encontra

\footnotetext{
${ }^{1}$ Docente da Universidade Federal de Rondónia, Museu de Favela MUF, IBRAM Instituto Brasileiro de Museus, Museu Histórico Nacional marcellepereira07@gmail.com
} 
terreno fértil nas interpretações propostas pela Sociologia das Ausências ao lidar com a desconstrução das ideias hegemônicas pautadas em reforçar a não existência produzida pela imagem do ignorante; do residual; do inferior; do local e do improdutivo. Buscase aqui evidenciar as possibilidades de construção de um diálogo aproximando este modelo de leitura sociológica do cenário da museologia social com destaque para algumas iniciativas da região Norte do Brasil.

Palavras chave: museologia social; sociologia das ausências; Amazônia Brasileira; museus.

\section{Abstract}

This article aims to establish a theoretical approach between the Social Museology and assumptions of Sociology of Absences, from a preliminary analysis of the concepts of monoculture and ecology conveyed by Portuguese sociologist Boaventura de Souza Santos. Monocultures are responsible for the proliferation of social invisibility and from them, ecologies arise as alternatives to enable the visibility of the silenced social practices and therefore, in forgetting process. The social museology, in turn, has been dedicated to transforming marginalized social processes narratives and museological initiatives that enable reflection and citizen participation from a perspective that includes the museum as a space that can act in the deconstruction of social forms of production of non-existence. Thus, social museology finds fertile ground in the interpretations proposed by the Sociology of Absences to deal with the deconstruction of hegemonic ideas guided to strengthen the non-existence produced by the ignorant image; residual; lower; local and unproductive. Search is here to 
highlight the possibilities of building a dialogue approaching this sociological interpretation model of social museology scenario highlighting some initiatives of northern Brazil.

Key words: social museology; sociology of absences; Brazilian Amazon; museums.

\section{Sociologia das Ausências e a Museologia Social: primeiras aproximações.}

Para o sociólogo português Boaventura de Souza Santos, a indignação é a revolta contra um estado de coisas particularmente vergonhosa ou cruel, em nome de uma ética ou de uma política que nos faz pensar que merecemos algo melhor. Assim, a prática da indignação pressupõe a crença na possibilidade de que a realidade pode mudar, ou seja, é a capacidade que temos de gerar mudanças, pois ao nos indignarmos podemos investir esforços em alterar realidades. Sabiamente o autor nos apresenta a ideia de que ao aceitarmos, sem conflitos e questionamentos, as condições que infligem direitos e a dignidade humana estamos exercitando a capacidade da resignação que não permite avanços e mudanças concretas. (SANTOS, B, 2012).

Assim, a capacidade de gerar indignação inspira a museologia social e permite estabelecer novas formas de compreensão do papel da museologia frente aos desafios sociais que vivenciamos atualmente. $O$ entendimento de que a indignação pode ser considerada acervo permite que a museologia social se aproxime da Sociologia das Ausências, pois esta é, segundo Boaventura "uma investigação que visa demonstrar que o que não 
existe é, na verdade, ativamente produzida como não existente... O objetivo da sociologia das ausências é transformar objetos impossíveis em possíveis, objetos ausentes em presentes" (SANTOS, B, 2004, p. 15).

Neste contexto, para o autor, as ausências são produzidas para manter distante tudo que não está de acordo com as ciências sociais convencionais e afirma que a formulação de questões que levam em consideração sujeitos e temas tidos como inexistente é uma postura que pode ser considerada um rompimento com a produção de conhecimento científico tido como oficial e legítimo. Para melhor caracterizar a sociologia das ausências, Boaventura de Souza Santos apresenta cinco formas sociais de produção da não existência, atribuídos à epistemologia e a racionalidade hegemônica. São elas: 1) o ignorante; 2) o residual; 3) o inferior; 4) o local e 5) o improdutivo. Estas categorizações são fruto de reflexões baseadas em monoculturas estabelecidas para buscar compreender a produção de invisibilidade e estão respectivamente relacionadas com: 1) a monocultura do saber e do rigor do saber; 2) a monocultura do tempo linear; 3) a monocultura da naturalização das diferenças; 4) monocultura do universal e do global; 5) monocultura dos critérios de produtividade (SANTOS, B, 2002).

Para Boaventura, a monocultura do saber e do rigor do saber, é a mais poderosa forma social de produção da não existência e:

Consiste na transformação da ciência moderna e da alta cultura em critérios únicos de verdade e qualidade estética, respectivamente. A cumplicidade que une as duas culturas reside no facto de ambas se arrogarem ser, cada uma no seu campo cânones, exclusivos de produção de conhecimentos ou de criação artística. Tudo que o cânone 
não legitima ou não reconhece é declarado inexistente. A não-existência assume a forma aqui de ignorância ou de incultura (SANTOS, B, 2004, pág.: 12).

Assim, podemos perceber o poder que se pode conferir ao conhecimento. A legitimidade do saber define as condições em que sujeitos podem expor pensamentos e de que forma o conhecimento será posto em sociedade. $\mathrm{O}$ inculto não pode contribuir com a sociedade em que vive, a produção do ignorante é importante para a supervalorização das ideias do culto.

A barreira criada permite produzir a invisibilidade de saberes construtores de identidades e de culturas pautadas em conhecimentos distintos daqueles canonizados pela ciência oficial. É - caso dos vários conhecimentos tradicionais indígenas, quilombolas e ribeirinhos, povos e comunidades da Região Norte, por exemplo. Seus modos de conceber a vida e o mundo são tidos como elementos simbólicos e culturais que geram apenas curiosidade de um modo geral. Esta é uma armadilha cruel e bem tecida que encontra respaldo em correntes teóricas e pensamentos solidamente constituídos.

A monocultura do tempo linear é caracterizada pela ideia de que a história possui um único sentido e uma única direção e, dessa forma dá sentido ao que chamamos de progresso, revolução, modernização, desenvolvimento, crescimento e globalização. A ideia de que o tempo é linear corrobora com a justificativa dos países sempre a frente de seu tempo, produzindo conhecimentos válidos e certificados, instituições legitimadas e formas de sociabilidade determinadas. Para o autor "Esta forma produz nãoexistência declarando atrasado tudo que, segundo a norma 
temporal, é assimétrico em relação ao que é considerado avançado" (SANTOS, B, 2004, pag. 13).

A este respeito é importante destacar a produção da ideia de atraso econômico, cultural e social da região amazônica. É comum pessoas perguntarem se é normal ver animais selvagens pelas ruas, ou encontrar índios nus com frequência. Com uma visão romântica e preconceituosa, se constrói um imaginário que coloca a região em situação de atraso e de despreparo diante dos grandes centros e capitais produtores de conhecimentos avançados.

Quanto à monocultura que diz respeito à naturalização das diferenças, segundo o autor: "consiste na distribuição da população em categorias que naturaliza hierarquias. A classificação racial e sexual são as mais salientes manifestações desta lógica (SANTOS, B, 2004, pag. 13)." Assim, considera que a não existência é resultado da produção de uma inferioridade insuperável por que é considerada natural e quem é inferior nunca pode chegar a ser superior. (SANTOS, B, 2004).

Já a monocultura universal e global pressupõe uma lógica que consiste em considerar a escala escolhida para ser a primordial como determinante e todas as outras escalas possíveis são irrelevantes. Assim Boaventura explica que:

A globalização é a escala que nos últimos vinte anos adquiriu uma importância sem precedentes nos mais diversos campos sociais. Trata-se da escala que privilegia entidades ou realidades que alargam o seu âmbito para todo o globo e que, ao fazê-lo, adquirem a prerrogativa de designar entidades ou realidades rivais como locais. (SANTOS, B, 2004, pag. 14). 
A última monocultura apresentada pelo autor é a que se refere aos critérios de produtividade e está atrelada a fabricação da não existência quando determina a improdutividade, no que se refere ao homem preguiçoso, à incapacidade profissional ou quando se refere à natureza esta monocultura está atrelada a produção da esterilidade (SANTOS, B, 2004).

Assim, de maneira explícita compreendemos que 0 ignorante, o residual, o inferior, o local e o improdutivo são frutos destas monoculturas quando propõem que as ausências são construídas para que o foco das questões sociais esteja sempre pautado nas realidades consideradas relevantes, sejam elas científicas, avançadas, superiores, globais e ou produtivas (SANTOS, B, 2002, 2004, 2005, 2010).

A proposta veiculada pela sociologia das ausências pretende identificar e transformar estas experiências produzidas como sendo ausentes em possibilidades concretas de construção social, ou seja, tornando-as presentes. Dessa maneira estas ausências produzidas pelo esquecimento proposital passam a presenças, sendo respeitadas como alternativas para a experimentação social confrontando as experiências consideradas hegemônicas.

A sociologia das ausências visa, assim, criar uma carência e transformar a falta de uma experiência social em desperdício da experiência social. Com isso cria as condições para ampliar o campo das experiências crediveis neste mundo e neste tempo e, por esta razão, contribui por ampliar o mundo e dilatar o presente. A ampliação do mundo ocorre não só por que aumenta o campo das experiências credíveis existentes, como também porque, com elas, aumentam as possibilidades de experimentação social no futuro (SANTOS, 2004, pag. 15). 
Para o autor a sociologia das ausências é necessariamente transgressiva e, sendo assim, pretende identificar e superar concepções de totalidade pondo em questão cada um dos modos de produção de ausências acima descritos.

Buscando alternativas para o enfrentamento da produção de não existência, Boaventura de Sousa Santos propõe por em prática o exercício das seguintes ecologias: 1) a ecologia dos saberes; 2) a ecologia das temporalidades; 3) a ecologia dos reconhecimentos; 4) a ecologia das trans-escalas e 5) ecologia das produtividades. Pautadas pela ação objetivam privilegiar uma postura que valoriza a multiplicidade de práticas sociais dando-Ihes credibilidade para serem encaradas como alternativas legítimas de produção de conhecimentos e trocas sociais.

A ecologia dos saberes põe em questão a monocultura do saber e do rigor científico ao propor que outros saberes, produzidos em contextos e práticas sociais declarados não-existentes sejam considerados com credibilidade diante dos saberes ditos "legítimos" cientificamente. Por meio da ideia de que os saberes não científicos são alternativos ao saber científico, corrobora-se com a subalternidade dos conhecimentos não científicos (SANTOS, B, 1995). Espera-se, por meio da prática da ecologia do saber, superar este raciocínio e "provar que não há ignorância em geral nem saber em geral. Toda ignorância é ignorante de certo saber e todo saber é a superação de uma ignorância em particular (SANTOS, B, 1995: 25)".

No domínio da ecologia das temporalidades a sociologia das ausências visa libertar as práticas sociais das amarras do tempo linear medido hierarquicamente e praticante de uma dominação resistente. A ideia é incentivar que as práticas sociais "nãoexistentes" possam retomar a sua própria temporalidade e 
autonomia diante da afirmação de que as sociedades são constitutivas de várias temporalidades e que muitas são consideradas não-existentes por "extravasar o cânone temporal da modernidade ocidental capitalista" (SANTOS, B, 2004, pag. 18).

No que se refere à ecologia das trans-escalas esta é uma tentativa de "desglobalização" do local, ou seja, uma ampliação das possibilidades de entendimento de um "globalismo" localizado. Conforme o autor:

A sociologia das ausências exige neste domínio o exercício da imaginação cartográfica quer para ver em cada escala de representação não só o que ela mostra, mas também o que ela oculta quer para lidar com mapas cognitivos que operam simultaneamente com diferentes escalas, nomeadamente para lidar com as articulações locais/globais (SANTOS, B, 1995: 456-473)

Por último à lógica da classificação social e, por conseguinte, a produção da desqualificação dos agentes e de suas práticas sociais (saberes e fazeres) produzindo iguais e diferentes segundo os pressupostos do poder capitalista moderno e ocidental, garante o determinismo de ditar quem é igual e quem é diferente. Com o intuito de desconstruir esta lógica que produz desqualificação social a ecologia do reconhecimento procura uma nova articulação entre o princípio da igualdade e da diferença, abrindo espaço para as diferenças iguais e para o exercício dos reconhecimentos recíprocos (SANTOS, B, 2004, pag. 18).

Dessa maneira a sociologia das ausências busca garantir a visibilidade de realidades que são produzidas como ausentes por via da produção de invisibilidade e silenciamento e também do processo de discriminação, provocando "a diversidade e 
multiplicidade das práticas sociais e credibilizar este conjunto por contraposição à credibilidade exclusivista das práticas hegemônicas" (SANTOS, B, 2004, pág 18).

Ao atentarmos para o fato de que as ecologias buscam o enfrentamento de ideias embasado na tese de que vivemos um período de transição de paradigmas, que atinge o mundo de uma maneira geral (SANTOS, B, 2004), podemos crer no desenvolvimento dos processos de emancipação como instrumento necessário e uma alternativa viável para o enfrentamento das estratégias que se utilizam da produção científica oficial para excluir e marginalizar a produção de conhecimentos alternativos cerceando, dessa maneira, o reconhecimento de diferentes saberes, práticas e atores sociais.

Assim, produzir práticas emancipatórias que se contraponham ao universo coercitivo a que são submetidas às narrativas e a produção cultural dos grupos marginalizados é uma das saídas para a construção de um novo senso comum, onde as ideias de solidariedade e participação podem contribuir para uma nova conjuntura social pautada na renovação da teoria crítica contribuindo com a reinvenção da chamada emancipação social (SANTOS, B, 1999 e 2002).

Dessa maneira, inspirada pelo desejo de promover espaços de diálogo pautados em ideias de participação e solidariedade a museologia dialoga com a sociologia das ausências, em várias perspectivas e pode ser enquadrada diretamente como espaço de experimentação e atuação das ecologias acima descritas. Diferentes movimentos sociais e comunidades encontram nos museus um território propício para a manifestação de suas insatisfações e enfrentamento de injustiças sociais. 
A luta pela garantia do direito à memória de grupos negligenciados passa a ser prioridade para os movimentos na medida em que esta valorização e identificação das memórias que retratam as dificuldades, lutas, resistências e conquistas, inaugura uma possibilidade de reconhecimento, visibilidade e transformação onde os resultados podem ser vistos, contemplados e postos a conhecer por um maior número de pessoas. Os movimentos sociais se fortalecem na medida em que suas reinvindicações e trajetórias passam a ser reconhecidos e debatidos em sociedade com maior profundidade. Como instrumento didático e de veiculação midiática os museus tornam-se aliados poderosos no jogo de perpetuação das memórias e do poder das memórias.

Neste sentido, acreditamos que a ênfase deve ser dada ao fato de que não se trata de uma supervalorização da memória dos grupos oprimidos, ou incluídos no rol dos não-existentes, nem tão pouco alimentar a crença de uma autenticidade pretérita (SARLO, 2007). Ponderamos que as práticas de museologia social, empreendidas ou não por movimentos sociais devem considerar a linha tênue que separa as narrativas múltiplas e polifônicas das narrativas unificadas que identificam um passado escolhido como testemunho da própria legitimidade da memória (ABREU, CHAGAS \& SANTOS, 2007).

Na medida em que o campo da memória e patrimônio vem sendo amplamente discutido e debatido, especialmente no que se refere aos patrimônios locais, podemos perceber que a discussão sobre a proteção e preservação do patrimônio no século XXI está relacionada ao medo do desaparecimento e ao fortalecimento das culturas provenientes de populações tradicionais. A esse respeito Regina Abreu, propõe pensarmos em uma "patrimonialização das diferenças" dando conta de um movimento que pretende atentar 
para a riqueza do diferente presente nas populações tradicionais expressas em suas culturas, modos de fazer, ser e saber. (ABREU, 2010). A patrimonialização que a autora se refere, possui tom de alerta, pois desperta para uma grande discussão de direitos sobre a produção de conhecimentos e a garantia de autonomia diante da produção de tecnologias tradicionais. As lutas das minorias e dos grupos vulneráveis socialmente, também podem ser inseridas como igualmente importante e necessária pautada por questões contemporâneas de garantia de direitos negados, discriminação e intolerância para as diferenças de religião, cor, condição sexual e tantas outras.

Assim, aproveitando o termo proposto pela autora, propomos pensar em uma "musealização das diferenças" estreitamente relacionada com a ecologia do reconhecimento, proposta por (SANTOS, B, 1999, 2002, 2004). Importa perceber que este processo de musealização pode ser propagado pelos variados processos museais que exercitam a salvaguarda do direito a ser diferente, o direito a tolerância e principalmente o direito a outros espaços de narrativa, considerados como acervo, objetos de estudos e de interesse da museologia social.

Os museus ampliam o potencial e a capacidade de romper com uma tradição que valoriza apenas discursos unilaterais que visam promover uma regulação social insistindo em projetar o conhecimento científico como verdades estabelecidas, para encarar o desafio de fazer valer a concepção de museu que valoriza a ideia de emancipação do sujeito valorizando a construção de sua própria história por meio da participação e do exercício da indignação.

É importante mencionar que esta concepção de museu é debatida a partir da Mesa de Santiago do Chile, ocorrida em 1972, promovida pelo ICOM, Conselho Internacional de Museus. Este 
momento inaugura uma nova concepção museológica pautada, especialmente, pela necessidade de atuar frente às questões sociais contribuindo para a transformação do mundo por meio dos museus e sua atuação crítica (MOUTINHO, 2007). Considerada um marco, sua atualidade e seus propósitos são fonte de entusiasmo criador e de estudos para o debate em torno da museologia social. Seu documento final apresenta as bases conceituais e filosóficas do que se denominou, posteriormente, de Movimento da Nova Museologia - MINOM.

Este diálogo inaugurado pela Mesa de Santiago do Chile, fortemente inspirado pelo contexto libertário e de contestação vivido pelo mundo em fins da década de 1960 e 1970, impulsiona uma discussão que desloca de modo significativo à maneira de pensar os museus e a museologia:

Começa-se a se delinear, em Santiago, talvez de forma não intencional, o que em nosso entender, é o marco mais significativo da evolução do processo museológico na contemporaneidade: a passagem do sujeito passivo e contemplativo para o sujeito que age $e$ transforma a realidade. Nessa perspectiva, o preservar é substituído pelo apropriar-se e reapropriar-se do patrimônio cultural, buscando a construção de uma nova prática social (SANTOS, Maria Célia Moura, 2002: 111).

Assim, diante destas possibilidades de atuação que levam em consideração uma museologia a favor da autonomia dos grupos sociais diante de seus patrimônios, de suas narrativas e identidades culturais, compreendemos que o terreno para crescimento e experimentações do campo da Museologia Social Brasileira é vasto e promissor e está configurado pelo interesse no debate em torno 
das discussões a favor da ampla garantia por direitos e na criação de contextos interativos de comunicação pautados na reinvindicações de populações e grupos vulneráveis. Os movimentos sociais, nesse caso, utilizam a potência geradora dos museus a serviço de seus ideais e projetos de poder.

Assim, é importante observar que:

Não se tratava mais, tão-somente, de abrir os museus para todos, mas de admitir a hipótese e de desenvolver práticas em que o próprio museu, concebido como um instrumento ou um objeto poderia ser utilizado inventado e reinventado com liberdade, pelos mais diferentes atores sociais. Por essa estrada, o próprio museu passou a ser patrimônio cultural e o patrimônio cultural uma parte constitutiva da nova configuração museal. (CHAGAS, M. S. 2007, pág. 220)

Diante da perspectiva de que os museus podem e devem ser inventados e reinventados por diferentes grupos sociais, consideramos, assim, como a Sociologia das Ausências que visa "revelar a diversidade e a multiplicidade das práticas sociais e credibilizar este conjunto por contraposição à credibilidade exclusivista das práticas hegemônicas (SANTOS, B, 2004. Pág. 22)", que a Museologia Social igualmente pode contribuir para retirar do esquecimento e da produção forçada de não existências as práticas sociais silenciadas e marginalizadas. Por meio dos processos de musealização criam-se estratégias que permitem a visibilidade das memórias produzidas garantindo o diálogo e o enfrentamento de ideias.

Os museus tornam-se aliados da Sociologia das Ausências, quando atuam como espaços construtores de narrativas 
apresentadas desde o ponto de vista dos esquecidos e ausentes da produção social considerada legítima. Ao se apropriarem da ferramenta museu como fonte de experimentação para a sociologia das ausências, sugeridas por Boaventura de Sousa Santos, compreendemos que as ecologias propostas podem se tornar linguagem, inspiração e arcabouço teórico para o campo da museologia social nesta batalha contra os esquecimentos produzidos de forma incomensurável.

Sociologia das Ausências e a Museologia Social: experimentações no contexto da Amazônia Brasileira.

A Região Norte do país recortada por bacias hidrográficas fantásticas, natureza exuberante de profundo verde esconde entre suas riquezas naturais uma disputa insensível, cruel, e truculenta que desrespeita a dimensão humana. Durante gerações este cenário tem sido alvo da ganância humana desmedida. As trilhas, rios e afluentes deste território têm sido testemunhas desta desleal disputa. No entanto, ao longo dos anos variados movimentos sociais se articulam e lutam em busca de respeito e dignidade para os povos da floresta.

Como exemplo, podemos citar a disputa por recursos da natureza que ano após ano mata e destrói grupos e comunidades tradicionais que vivem da terra e que a respeitam acima de qualquer coisa. Sem a intenção de promover aqui uma visão romântica, pois consideramos as tensões presentes nestas realidades, podemos aferir que são muitas as injustiças para os moradores desta região, principalmente os indígenas e ribeirinhos. No entanto, podemos constatar que ao longo das últimas décadas alguns movimentos sociais se alimentam de tais indignações e 
batalham para diminuir as desigualdades e o descaso com que são tratados diante de interesses de grupos dominantes economicamente.

Nesse contexto o campo da museologia social vê surgir experiências que garantem oxigênio para que os museus estejam presentes nas vidas, no cotidiano e nas lutas sociais contribuindo com uma visão de mundo pautada pela força das memórias. Tais práticas museais ganham o mundo e rompem uma barreira de invisibilidade e se destacam no cenário nacional e internacional que vem revelando em rede um potencial extraordinário de atuação.

Dessa maneira, ainda com relação ao escopo teórico da museologia social destacamos que os museus e processos museais permitem o diálogo e a identificação da diversidade de práticas sociais e possibilidade de relações não destrutivas entre os agentes produtores de memória e cultura, pautadas no direito à memória e nas narrativas plurais. Com base nas discussões propostas pela sociologia das ausências, as práticas de museologia social podem ser pautadas pelas estratégias de enfrentamento sugeridas pelas ecologias do saber, das temporalidades, do reconhecimento, das trans-escalas e da produtividade.

Ao propor narrativas livres de discursos oficiais, com base em discussões que ressaltem a cidadania e a promoção da dignidade humana, que visem à participação comunitária efetiva nas decisões e propostas museográficas e que garantam as definições e utilizações cada vez mais diversificadas dos acervos, os museus e processos museais agem a favor de uma ruptura com as práticas de poder hegemônicas e limitadoras propondo outras leituras a partir do ponto de vista dos grupos com direitos subtraídos e desrespeitados produzidos como não existentes, e, por conseguinte, esquecidos. 
Conforme sugere Mário de Souza Chagas:

O que está em jogo nos museus e também no domínio do patrimônio cultural é memória, esquecimento, resistência e poder, perigo e valor, múltiplos significados e funções, silêncio, fala, destruição e preservação. E por tudo isso interessa compreendê-los em sua dinâmica social e interessa compreender o que se pode fazer com eles, contra eles, apesar e a partir deles. (CHAGAS, 2003. Pág: 58-59).

Dessa maneira, é importante destacar que os museus assim como podem contribuir com a produção de presenças podem igualmente produzir ausências quando reforçam os discursos da "não existência" já discutidos anteriormente no âmbito das monoculturas, segundo concepção de Boaventura de Sousa Santos. Os museus são ferramentas que podem ser utilizadas para usos diferentes (CHAGAS, 2010). O que importa é a concepção que dará forma as práticas e processos museais. Tudo depende da intenção.

Partindo desta concepção de museu e de museologia observamos que a Região Norte do Brasil é espaço e cenário de muitas práticas da museologia social em desenvolvimento. Algumas já estão institucionalizadas como museus e outras caracterizadas como processos museais pautadas em ações de memória e cidadania, mas que não se organizam como museus.

Para este texto faremos referência breve e introdutória a algumas iniciativas de museologia social situadas na Região Norte do país, ressaltando a vocação para a indignação, a aproximação com o campo da educação e o compromisso com o fortalecimento das comunidades público alvo e protagonistas das experiências. 
O Ecomuseu da Amazônia, a Casa de Chico Mendes, o Museu Sacaca e o Museu Magüta são iniciativas que legitimam reivindicações, memórias de vida e os saberes marginalizados, procurando retirá-los do estado de não existência que é produzido pela lógica das Monoculturas trazendo de volta sob uma perspectiva critica e desafiadora da ordem única vigente. A partir destas experiências, tecemos um diálogo que aproxima o campo da museologia da teoria sociológica das ausências.

\section{Ecomuseu da Amazônia}

Estreitamente relacionado com as práticas educacionais, foi criado no âmbito da Secretaria Municipal de Educação e vinculado a Escola Bosque Professor Eidorf Moreira, situado em Belém do Pará, o Ecomuseu da Amazônia tem se dedicado ao desenvolvimento de trabalhos que visam à participação popular e a construção de projetos de desenvolvimento humano sustentável que garantam os interesses das comunidades e a valorização de suas ações de natureza tradicional. A busca por transformações sociais faz com que o Ecomuseu se dedique a um trabalho de memória junto às ilhas de Cotijuba, Caratateua e Mosqueiro. Por meio de oficinas, aulas de música, horta orgânica, turismo sustentável de base comunitária e oficinas gastronômicas o Ecomuseu, persegue como missão a proposta de Hugues de Varine, quando este diz que o museu é um espelho onde a comunidade se olha para se reconhecer (ANAIS IV EIEMC, 2012).

As ações do Ecomuseu são dedicadas à valorização da memória coletiva, referencial básico para o entendimento e a transformação da realidade local. Os territórios de ação do Ecomuseu são distritos com características de abandono do poder público no que se refere a questões básicas necessárias. Os distritos 
são da cidade de Belém e foram alvo de ações específicas por parte da Secretaria de Educação e a Funbosque, no sentido de promover iniciativas educacionais. O Ecomuseu surge destas iniciativas e está pautado em três pilares: o território, a comunidade e o patrimônio. Sua sustentação está baseada em três princípios: sustentabilidade, subsidiariedade e responsabilidade. (ANAIS IV EIEMC, 2012).

As ações do Ecomuseu estão baseadas em um amplo Programa de Formação, denominado: Patrimônio e capacitação dos atores do desenvolvimento local, este programa define capacitação como sendo:

O conjunto de ações implementadas em uma comunidade para levar seus membros a valorizar, desenvolver e/ou adquirir os saberes, os fazeres, as práticas, as técnicas que lhes permitirão tomar nas mãos seu próprio desenvolvimento, quer dizer, a melhoria de suas condições de vida, de modo sustentável e responsável (ANAIS IV EIEMC, 2012, pág 47)".

A aproximação das ações do Ecomuseu da Amazônia com o campo da educação faz com que esta iniciativa contribua significativamente com as reflexões em torno da relação existente entre as práticas da museologia social, o campo da educação e os pressupostos da Ecologia de Saberes. A capacitação proposta pelo Ecomuseu propõe discussões com destaque para uma visão integral de território, pautado no respeito ao patrimônio, tido como matéria-prima para garantir sua sustentabilidade. O princípio norteador de que a capacitação oferece oportunidades para que os participantes se tornem gestores de seus próprios patrimônios é também responsável pelo papel de mobilização e articulação 
exercido antes, durante e depois das oficinas e atividades de formação.

É próprio da natureza da ecologia de saberes constituir-se através de perguntas constantes e respostas incompletas. Aí reside a sua característica de conhecimento prudente. A ecologia de saberes capacitanos para uma visão mais abrangente daquilo que conhecemos, bem como do que desconhecemos e também nos previne para que aquilo que não sabemos é ignorância nossa e não ignorância em geral (SANTOS, B, 2010: 66).

Cultura, turismo ambiental e cidadania são os eixos de atuação dos programas de formação do Ecomuseu e por meio deles o museu incentiva o rompimento com as tradições das monoculturas do saber promovendo outras possibilidades de construção de conhecimentos pautados no protagonismo dos grupos e das comunidades a fim de ampliar as possibilidades de ação e transformação de seu território cultural e social.

Museu Sacaca

Outro exemplo inspirador que permite aproximar suas práticas dos pressupostos da Ecologia de Saberes é o Centro de Pesquisas Museológicas - Museu Sacaca, vinculado ao Instituto de Pesquisas Científicas e Tecnológicas do Estado do Amapá. O Museu desenvolve suas ações, pautado por experiências que pretendem promover o patrimônio cultural em parceria com as comunidades indígenas, ribeirinhas, extrativistas e produtoras de farinha e como resultado desta parceria surgiu à exposição a Céu Aberto do Museu Sacaca.

Baseado em ambientações que recriam os modos de vida e costumes das comunidades o circuito expositivo do museu desperta 
o interesse dos visitantes que tem a oportunidade de se relacionar de maneiras diferentes com a produção de conhecimentos de natureza tradicional do Amapá. O Centro de Pesquisas Museológicas desenvolve ações de pesquisa, preservação e comunicação dos patrimônios com vistas a ampliar a discussão e reflexão sobre o saber popular e suas articulações com a produção de saber científico.

Sua trajetória tem origem na fusão de dois acervos oriundos do Museu de História Natural Ângelo Moreira da Costa Lima e o Museu de Plantas Medicinais Waldomiro de Oliveira Gomes. O Museu Sacaca é uma homenagem a Raimundo dos Santos Souza (19261999), o "Sacaca", curandeiro local de grande importância para a difusão da medicina natural junto à população amapaense ${ }^{2}$.

O Museu Sacaca possui um cenário cercado pelo imaginário das florestas e com toda a sua força promove a valorização dos modos de ser e fazer das comunidades tradicionais permitindo um intercâmbio de ideias e de práticas pautado no respeito mútuo e fortalecimento das identidades locais. O museu tem nome de curandeiro, tem casa de farinha, passeio com o Regatão denominado Milagres de Nossa Senhora, a réplica da casa de ribeirinho e uma casa típica Wajãpi feita pelos próprios índios e todas as suas ações possuem ênfase para as práticas sociais locais. Para Santos, "a ecologia dos saberes, deve formular-se assim: deve dar-se preferência às formas de conhecimento que garantam a maior participação dos grupos sociais envolvidos na concepção, na execução, no controle e na fruição da intervenção" (SANTOS, B, 2010, p. 60).

${ }^{2}$ Informações obtidas no link:

http://www.agenciaamapa.com.br/site/museusacaca/207 


\section{Casa de Chico Mendes}

No que se refere à Casa de Chico Mendes esta pode ser considerada uma grande fonte de inspiração para a museologia social na Região Norte. Casa simples, que carrega em seu interior uma força eloquente quando o assunto é movimento social e militância. Seu dono, ainda hoje é símbolo de vida e sua memória segue nos alimentando de indignação e de persistência. Sua casa é um museu, é carregada de memória e também é ação.

$\mathrm{O}$ espaço onde foi à casa do ativista Chico Mendes contribui atualmente com a permanência da imagem de Chico Mendes como grande revolucionário e uma das principais lideranças do sindicalismo rural na Amazônia Brasileira. No entanto, muitos são os movimentos e interesses, que dedicam esforços para que a imagem de Chico Mendes seja perpetuada apenas como um grande "ambientalista". Para Elder Andrade de Paula e Silvio Simione da Silva a figura de Chico Mendes foi manipulada a fim de provocar o que os autores chamam de "transmutação habilmente articulada pelo Estado (no sentido ampliado) na tentativa de re-significar a natureza e a cultura para fins de legitimação da ideologia do "desenvolvimento sustentável" e assim, facilitar o processo de espoliação em curso na Amazônia" (PAULA \& SILVA, 2008 pág. 102).

O legado revolucionário e indignado de Chico Mendes não serve aos interesses especialmente comerciais depositados sobre a Amazônia Brasileira. Neste caso é mais apropriado que tenha existido uma figura pacifica que dedique seu tempo a grande batalha ambiental unicamente do que um homem forte disposto a denunciar as barbáries cometidas contra a condição rural da Amazônia.

Movimentos sociais como a Via Campesina, representam o fortalecimento e principalmente a retomada das discussões em tom 
mais apropriado para o tamanho dos desafios enfrentados pela Região Norte contra os facínoras que destroem a Amazônia e contra os discursos que pretendem legitimar a ideologia do "desenvolvimento sustentável" sem levar em conta as lutas e resistências a favor e pelo direito a terra (PAULA \& SILVA, 2008).

Segundo o Instituto do Patrimônio Histórico e Artístico Nacional - IPHAN, a Casa de Chico Mendes:

É um imóvel simplório, que obedece a um sistema construtivo tradicional da região, ainda de uso frequente. A casa cabloca em madeira coberta de telha de barro possui apenas $4 \mathrm{~m}$ de largura e pode ser edificada em menos de uma semana. Todo composto de tábuas verticais, inclusive as portas e janelas, o imóvel possui telhado em formato de $V$, de telha francesa ${ }^{3}$.

Esta casa surge como instrumento de luta, como marco de uma ideologia e missão construídas a favor da floresta e de sua manutenção respeitosa, utilizando para isso a memória do homem Chico Mendes com o intuito de possibilitar a compreensão das causas pelas quais lutava. Musealizada eterniza a morte por assassinato do seu dono e torna-se absolutamente testemunha, referência e símbolo.

A reinvenção da emancipação social, proposta por (SANTOS, 2004), nos permite perceber outras possibilidades de atuação onde os movimentos sociais e suas lutas por garantias de direitos criam alternativas contra-hegemônicas em espaços reais de democracia

\footnotetext{
${ }^{3}$ Informações obtidas no link:

http://portal.iphan.gov.br/portal/montarDetalheConteudo.do?id=13936\&sigla=Ins titucional\&retorno=detalhelnstitucional
} 
participativa. A Casa de Chico Mendes musealizou a capacidade de seu dono de provocar pequenas revoluções e segue legitimando as lutas a favor de uma sociedade mais indignada socialmente.

Museu Magüta

Localizado na cidade de Benjamin Constant, próximo à fronteira do Brasil com a Colômbia e o Peru, começou a surgir ainda em 1985, em assembleia dos Tikuna preocupados com o preconceito, rejeição e perseguição que sofriam. Inspirados pelo desejo de serem respeitados por sua cultura e tradição, viam no museu uma alternativa para a mudança de atitude da população. Dessa maneira, demonstrar por meio de recursos museográficos a sua cultura material e imaterial traria novos contornos aos conflitos enfrentados e novas perspectivas de diálogo pacífico.

Mobilizados na luta pela defesa de seu território os Tikuna enfrentaram pistoleiros em uma emboscada no Igarapé do Capacete, no ano de 1988 que mata 14 deles entre homens, mulheres e crianças, fere 23 e deixa 10 desaparecidos, num massacre que teve ampla repercussão nacional e internacional (FREIRE, 1999). Esse episódio marca a trajetória dos Tikuna e os impulsiona na tentativa de apresentar com base em documentos, seu direito a terra e ao respeito por sua cultura e tradição.

Em meio aos conflitos pela posse das terras, madeireiros, posseiros, pescadores e indígenas seguem desafiando os limites da convivência e acirrando os embates preconceituosos. As ações do Museu Magüta são desenvolvidas a partir de meados de 1990, dentro deste contexto de conflito e disputa. No entanto, diante de uma ampla mobilização popular o Museu venceu barreiras e preconceitos, resistiu a inúmeras tentativas de boicote e até ameaças de incêndio. Até os dias de hoje persiste frente a inúmeros desafios e um deles diz respeito a sua gestão. Sem apoio 
institucional vive do incentivo ao artesanato para conseguir arrecadar o mínimo necessário para que suas ações tenham continuidade.

O processo de constituição do museu foi pautado por grande mobilização por parte dos índios que contribuíram com objetos doados e produzidos especialmente para a exposição. A participação dos Tikuna nas atividades do Museu foi algo expressivo e resultou em uma experiência museal que merece destaque no âmbito dos processos museais da museologia social. Nas palavras de Jussara Gomes Gruber que, como assessora, teve um papel decisivo na criação, planejamento e instalação do Magüta:

Para a montagem da exposição teve-se o cuidado de apresentar os objetos de maneira a não reforçar o estigma de atraso e "primitividade" que marca as populações indígenas de modo geral. Na ambientação das peças optou-se por recursos que podem ser vistos nos melhores museus do país. Assim, ao invés de se usarem palhas, esteiras e amarração de cipó, fabricaram-se painéis e cubos de madeira pintada e vitrine para proteger os objetos menores. A exposição apresenta um desenho leve, alegre, com recursos museográficos que visam produzir um impacto de natureza cognoscitiva e estética, de modo a valorizar a riqueza e a complexidade da cultura Tikuna (GRUBBER, 1994, pág. 90 APUD FREIRE, 1999).

Assim, a partir da ideia de que os museus permitem as narrativas das suas próprias memórias e o reconhecimento de identidades, os Tikuna seguem apostando no fortalecimento de suas lutas por direitos. Como disse o Ticuna Liverino Otávio: “o 
Museu Magüta serve para guardar nosso futuro". (Boletim do Museu Magüta mai/out de 1993 Apud FREIRE, 1999).

O Museu Magüta uma experiência de museologia social no coração do território amazônico contribui para o exercício da ecologia dos reconhecimentos, ao propor com suas ações a qualificação de seus agentes e o reconhecimento das diferenças como legítimas e produtoras de culturas. A desqualificação das práticas e dos saberes produzidos pelos agentes e mais ainda a desqualificação dos próprios agentes, é uma das armadilhas da produção de invisibilidades que a ecologia dos reconhecimentos tenta ultrapassar. O Museu, por meio de sua narrativa pautada nas referências Tikuna e sua linguagem expositiva criada por Tikunas, inaugura uma forma de enfrentamento ao não reconhecimento a que são submetidos os povos indígenas. Sua ancestralidade, costumes e práticas ganham espaço de poder que legitima as memórias Tikuna e produz, assim, visibilidade.

\section{Considerações}

As aproximações entre os pressupostos da museologia social e os desafios da Sociologia das Ausências foram inspiradas pelo trabalho de Boaventura de Souza Santos, que traz reflexões pautadas no resultado de ampla pesquisa que envolveu vários países, entre eles o Brasil, e se refere a uma proposta de reinvenção da emancipação social. A partir da ênfase aos conflitos estabelecidos entre o Norte/Sul, buscou desenvolver alternativas epistemológicas que, entre outros desafios, tiveram em conta a necessidade de identificação de outros discursos e narrativas de mundo. E é sobre este aspecto que a museologia social tem se debruçado. Ao propor outras possibilidades de diálogos e espaços de enfrentamento social, a museologia, os museus e os processos 
museais corroboram com a proposta da Sociologia das Ausências e exercitam as ecologias a fim de produzir presenças e visibilidades do campo social brasileiro como vimos neste artigo.

Assim, compreendemos que lutas inteiras ainda precisam ser travadas e os museus aliados dos movimentos sociais devem estar unidos para provocar indignação, fomentar o diálogo e o enfrentamento com vistas ao respeito, empoderamento e emancipação social dos grupos e comunidades vulneráveis socialmente.

Nesta perspectiva encontramos atualmente no Brasil museus, museus comunitários, iniciativas de memória e processos museais que possuem articulações diversas em variados âmbitos, sejam movimentos nacionais, regionais ou locais, em associações, programas de governo que valorizam a memória e os processos museais, redes colaborativas de museologia social e memória e programas de extensão universitária. Estas articulações podem ser consideradas como resultados da atuação da museologia social com forte influência de movimentos internacionais como é o caso do Movimento Internacional da Nova Museologia - MINOM e de políticas públicas nacionais que valorizam a produção cultural viva e orgânica. São experiências que refletem uma mentalidade participativa, colaborativa que compreende os movimentos sociais como alternativas para conquistas de direitos e os museus como cenários para novos discursos e empoderamentos.

Por meio dos exemplos descritos percebemos que a prática da museologia social está focada em contribuir com a mudança de um mundo injusto, intolerante, preconceituoso e desatento que não enxerga e não valoriza a riqueza natural e diversidade social que possui. Dessa maneira, pretende movimentar opiniões, discursos e incentivar ações de enfrentamento. Os museus e os processos 
museais comprometidos com a museologia social propõem mudanças. Costurando estas práticas e descortinando tantas outras provocam e retiram da zona de conforto nossas memórias e nossos acervos de indignação promovendo outros futuros possíveis.

Interessada no material humano a museologia social persegue a ideia mais ampla de participação, mobilização e respeito ao diferente. Persiste ao propor e colocar em diálogo ideias opostas, conflitos e interesses sempre com a intenção de sacudir os marasmos de entendimentos únicos e omissos, opressores de sonhos e capturadores de vidas. Fonte de energia propulsora propõe a libertação das partículas mais simples de otimismo e responsabilidade. Em meio a um sem número de propostas castradoras de identidades, culturas, direitos civis e sociais, propõe um grito de alerta seguido por propostas concretas realizadas por aqueles que, por dentro de seus lugares, sentem-se corresponsáveis pelas transformações que procuram.

Consciente de todos os desafios ligados ao trato com as memórias compreende o jogo clássico entre opressor e oprimido, entre memória e esquecimento, entre poder agir e agir por poder. Os conflitos são inerentes às práticas sociais e não existe, nesse caso, ingenuidade quando propomos que as trocas e as interpretações postas em evidencia devem levá-los em consideração. O que justifica a prática da museologia social é mesmo o seu potencial de expor lacunas, ausências e advertências necessárias e muitas vezes postas de lado para defender ideias únicas em discursos unilaterais. O por em diálogo significa mais que dialogar com o novo ou com o não dito, significa demonstrar outros olhares e outras formas de compreender o jogo perpetuado de poder e de legitimidade que ofende a nossa diversidade e castra capacidades. 
Importa ouvir de outro jeito, importa conhecer outras formas, descrever e interpretar silêncios. Importa ocupar espaço no cenário cultural e social tendo como pano de fundo e contexto as memórias que compõem trajetórias e movimentações em busca de dignidade e garantia de direitos.

A prática da museologia social em consonância com a sociologia das ausências permite experimentações onde os grupos culturais e mobilizações sociais ganham espaço, voz e oportunidades diminuindo, dessa maneira, os espaços para a produção de invisibilidades e de ausências. Diminui-se, pelo menos em parte, as distâncias e alguns silêncios são desfeitos. Movimenta a dinâmica social da apropriação de memórias, narrativas, discursos e saberes. Produz presença

\section{Referências}

ABREU, Regina. A patrimonialização das diferenças: usos da categoria "conhecimento tradicional" no contexto de uma nova ordem discursiva. In: Inovação Cultural, Patrimônio e Educação. Organizadores: BARRIO, Ángel Espina. MOTTA, Antônio e GOMES, Mário Hélio. Recife: Fundação Joaquim Nabuco, editora Massangana, 2010.

ABREU, Regina e CHAGAS, Mario (Orgs.). Memória e patrimônio. Rio de Janeiro: DPGA, 2003.

CHAGAS, Mario de Souza Chagas. Educação em Museus: balanços e perspectivas. In: Anais do I Encontro Nacional da Rede de Educadores em Museus e Centros Culturais do Estado do Rio de Janeiro - Rio de Janeiro: Fundação Casa de Rui Barbosa, 2010. (Coleção FCRB Aconteceu; 10).

FREIRE, José R. Bessa. A descoberta do museu pelos índios. Terra das Águas - Revista semestral do Núcleo de Estudos Amazônicos da 
Universidade de Brasília, ano 1, n.1, sem.1999. Último acesso em 19 de maio de 2014.

file://C:/Users/User/Downloads/133 A Descoberta dos Museus pelos ndios.pdf

GOHN, Maria da Glória. Teorias dos movimentos sociais. Paradigmas clássicos e contemporâneos. São Paulo: Loyola, 1997. MOUTINHO, Mário. Definição evolutiva de Sociomuseologia. Proposta de reflexão. Comunicação apresentada no XII Atelier Internacional do MINOM. Lisboa: ULHT, 2007.

SANTOS, Boaventura de Souza. A crítica da razão indolente: contra o desperdício da experiência. - 4. ed. - São Paulo: Cortez, 2002.

. O Fórum Social Mundial: manual de uso. Madison:

Dezembro 2004. http://www.ces.uc.pt/bss/documentos/fsm.pdf (último acesso em junho de 2015).

(org.). Conhecimento prudente para uma vida decente. São Paulo: Cortez Editora, 2004.

Para uma sociologia das ausências e uma sociologia das emergências. In: Revista Crítica de Ciências Sociais, 63, Outubro de 2002: 237-280. Último acesso em junho de 2015

http://www.boaventuradesousasantos.pt/media/pdfs/Sociologia d as ausencias RCCS63.PDF

\& MENEZES, Maria Paula. Para além do pensamento abissal: das linhas globais a uma ecologia de saberes. In: Epistemologias do Sul. São Paulo: Cortez, 2010.

SANTOS, Myrian Sepúlveda dos \& CHAGAS, Mario de Souza. A Linguagem de poder dos museus. In: Museus, coleções e patrimônios: narrativas polifônicas/Regina Abreu, Mario de Souza Chagas, Myrian Sepúlveda dos Santos [organizadores]. - Rio de Janeiro: Garamond, MinC/IPHAN/DEMU, 2007. 
Cadernos de Sociomuseologia ${ }^{\circ}$ 6-2015

SANTOS, Maria Célia T. M. Encontros Museológicos: reflexões sobre a museologia, a educação e o museu. Rio de Janeiro: MinC, IPHAN, DEMU, 2008. (Coleção Museu, Memória e Cidadania, ㄲo 4).

- Reflexões sobre a nova museologia. In: Cadernos de Sociomuseologia n.18-2002.

SARLO, Beatriz. Tempo passado: cultura da memória e guinada subjetiva. São Paulo: Companhia das Letras; Belo Horizonte: UFMG, 2007.

PAULA, Elder Andrade de \& SILVA, Silvio Simione da. Movimentos sociais na Amazônia brasileira: vinte anos sem Chico Mendes. Revista NERA. Presidente Prudente Ano 11, no. 13 pp. 102-117 Jul.dez./2008. Acessado em junho de 2015:

file:///C:/Users/User/Downloads/1391-4000-1-PB.pdf 